\title{
Market Integration, Choice of Technology and Welfare
}

\author{
Jørgen Drud Hansen and Jørgen Ulff-Møller Nielsen* \\ Department of Economics \\ Aarhus School of Business \\ University of Aarhus \\ Denmark
}

*Corresponding author: Jørgen Ulff-Møller Nielsen, Department of Economics, Aarhus School of Business, University of Aarhus, Prismet, Silkeborgvej 2, $7^{\text {th }}$ floor, DK- 8000 Aarhus C, Denmark,

Tel: +45 89486343, Fax: +45 89 486197, E-mail: jum@asb.dk

Acknowledgments: We are grateful for valuable comments from Philipp Schröder; Aarhus School of Business, University of Aarhus; Frank Stähler, Univeristy of Otago; Daniel M. Bernhofen, University of Nottingham, and participants at seminars at the University of Otago; Leverhulme Centre for Research in Globalization and Economic Policy, University of Nottingham, and the Aarhus School of Business, University of Aarhus. 


\begin{abstract}
This paper develops an international trade model where firms in a duopoly may diversify their technologies for strategic reasons. The firms face the same set of technologies given by a trade-off between marginal costs and fixed costs, but depending on trade costs the firms may choose different technologies. Market integration may induce a technological restructuring where the firms either diversify their technologies or switch to a homogenous technology leaving jumps in welfare both in the home and foreign country. It is shown that with respect to global welfare Cournot Nash equilibria with homogeneous firms are in some cases inferior to Cournot Nash equilibria with heterogeneous firms. A small decrease in trade costs, which induces a switch from heterogeneous technologies to a homogeneous technology, reduces global welfare. Extensive reductions in trade costs allow for the traditional positive global welfare effects of market integration.
\end{abstract}

Keywords: Firm heterogeneity; duopoly, technology choice; market integration; welfare. JEL code: F12, F13 


\section{Introduction}

Firms within industries often use different technologies. The most obvious reason for intra-industry costs heterogeneity is different qualities of inputs, e.g. in management or different vintages of technology. However, different technologies may also arise in cases where the firms have access to the same set of technologies, but for strategic reasons they deliberately differentiate their technologies.

Different technologies influence firm sizes and in open economies also behaviour in the export market. The most productive firms are the biggest (larger output and revenues) and the firms most involved in exports compared with less productive firms. Empirically this pattern is well documented; see e.g. Bernhard et al. (2003), Bernhard and Jensen (2004), and Greenaway and Kneller (2005) for a survey.

The above issues on firm heterogeneity have been dealt with intensively in recent literature in international trade theory. The 'new-new' trade theory based on monopolistic competition introduces firm productivity for the individual firm as a stochastic outcome of an initial investment of sunk costs i.e. the firm heterogeneity is exogenously given; see Schmitt and Yu (2001), Montagna (2001), Melitz (2003), and Helpman et al. (2004). Several oligopoly international trade models similarly specify productivities and firm heterogeneity as being exogenously given; see e.g. Lahiri and Ono (1997), Falvey (1998), and Collie (2006). 
However, firm heterogeneity on oligopoly markets may also arise as a result of the individual firm's strategic decisions on technology. This is demonstrated in a duopoly model for a closed economy by Mills and Smith (1996) ${ }^{1}$. In their model the firms are ex ante identical as they choose among the same set of blueprints of technologies.

The aim of this paper is to generalize the model of Mills and Smith by including international trade. Two firms producing a homogeneous output are assumed to operate and both producers face an identical technology trade-off between a specialised capital intensive technology and a non-specialised labour intensive technology ${ }^{2}$. Between the two technologies a trade-off between marginal costs and fixed costs exist, i.e. the nonspecialised technology has high marginal costs, but low fixed costs, and the opposite holds for the specialised technology. The two firms are involved in a two-stage game where the firms first choose technology and then play Cournot on output in the second game. The producers are located in the same country termed the home country, but provide consumers in both the home and the foreign country. By exporting the producers incur variable trade costs as well as fixed market access costs.

The model allows for co-existence of different technologies. Market integration through a reduction in variable trade costs triggers in some cases a technological restructuring (and sometimes also a change of market structure in the foreign market) with implications for

\footnotetext{
${ }^{1}$ A recent oligopoly trade model for multi-product firms by Eckel and Neary (2006) associates costs differences with the firm's choice of number of product variants.

${ }^{2}$ Alternatively, we could call the two technologies; 'modern' and 'traditional'; 'high-tech' and 'low-tech'; or 'large scale' and 'small scale'. In case of economies of scope the two technologies could represent 'multi-product plants' and 'single-product plants' or 'flexible manufacturing' or' non-flexible manufacturing'.
} 
welfare in both countries. The results of the welfare analysis show that for some trade costs, where the firms are technologically homogeneous in the Cournot-Nash equilibrium, global welfare would have been larger in case of heterogeneous technologies.

While the model leads to a negative global welfare impact of a small reduction of trade costs in cases where it triggers a switch from heterogeneous technologies to a homogeneous technology, extensive reductions in trade costs allow for the traditional positive global welfare effects of market integration.

The paper is organized as follows. Section 2 develops the basic model. Market equilibrium is illustrated and cost structures consistent with co-existence of different technologies are described. Section 3 analyzes the impacts of market integration, i.e. a decrease of the variable trade costs on technology choice and welfare. Section 4 concludes.

\section{The basic model}

We look at a two-country, partial equilibrium model with two firms ( 1 and 2$)$ producing a homogeneous product. Both firms are located in the home country $H$ and the foreign country $F$ is thus a pure importing country of the specific good. The two countries are 
separated by specific trade costs $g$ per unit of the good, including transport and trade barriers costs.

\section{Demand}

Consumers are of the same type in each country. Each consumer has a utility function separable and linear in a numeraire good. This allows for a partial equilibrium analysis, since there are no income effects on the industry. The utility, $U$, is assumed to be quadratic and strictly concave in consumption $(q)$ of the good and by suitable choice of units of the consumption good, utility is specified by the function $U=a q-1 / 2 q^{2}+z$, where $z$ is the utility of all other consumption goods (see Singh and Vives, 1984: 547). The marginal utility is thus given by $\partial U / \partial q=a-q$. The two countries may differ with respect to market size i.e. number of consumers. Assuming for simplicity the number of consumers in the home country is normalized to 1 , and $S$ in the foreign country, total direct demands of the product in the two countries become:

$$
\begin{aligned}
& Q^{H}=\left(a-p^{H}\right) \\
& Q^{F}=S\left(a-p^{F}\right)
\end{aligned}
$$

where $Q^{j}$ is quantity demanded; $p^{j}$ consumer price $(j=H, F)$ and $S$ the number of consumers in the foreign country measuring the size of the foreign market relative to the home market. To restrain the number of cases to be analyzed we assume that the home market is at least of same size as the foreign market i.e. $S \leq 1$. 
Supply

The producers face ex ante the same set of blueprints of technologies based on a trade-off between marginal and fixed costs. To restrict the technology analysis, only two technologies are assumed relevant. ${ }^{3}$ The producer $i(i=1,2)$ may decide to produce the quantity $q_{i}$ at a plant with low (constant) marginal costs $(c)$, but then incurs high fixed costs $(f)$, or at a plant with high (constant) marginal costs $\left(c^{*}\right)$ and low fixed costs $\left(f^{*}\right)$. The total costs $C_{i}\left(C_{i}^{*}\right)$ for alternative technologies are thus given by:

$$
\begin{array}{rr}
C_{i}=c q_{i}+f & (i=1,2) \\
C_{i}^{*}=c^{*} q_{i}+f^{*} & (i=1,2)
\end{array}
$$

where $c^{*}>c$ and $f>f^{*}$.

More generally, the technology space reflects the specialization of the firm. By deepening the capital equipment, a producer raises the efficiency of the variable input and hence obtains low marginal costs at the expense of high fixed costs.

\section{Trade costs}

Given the relative size of the markets we assume that both producers are located in the home country and hence, the analysis leaves no room for reciprocal dumping behaviour. To operate in the foreign market, the home producers have to pay a variable trade cost at $g$ per unit of output sold in the foreign market and a market access fixed cost of

\footnotetext{
${ }^{3}$ This is similar to the analysis of Mills and Smith (1996). However, as mentioned by Mills and Smith, even in the case a continuous trade-off between fixed and variable costs exists, the relevant cost efficient technologies may reduce to two alternatives only, if the continuous technology set is insufficiently convex. In that case equilibria only support two extreme cases of minimal (maximal) fixed costs and maximal (minimal) variable costs. A limited number of 'variants' of technologies may also be due to a limited market size for investment goods when scale economies prevails in producing variants of specific capital equipment.
} 
marketing his products, $m .^{4}$ The variable trade costs capture transport costs as well as tariffs, duties and other institutional costs for selling in foreign markets. Fixed market access costs are the costs of participation in foreign markets independent of the volume of exports. It consists of the costs of acquiring information on foreign markets and of creating a distribution network in the foreign country. It may also be costly to adapt products to foreign markets to ensure they are conforming to the foreign standards and regulations (testing, packaging and labeling requirements). In a more general framework, where the importing country hosts domestic producers in the industry, such costs may even be manipulated by governments to function as protection of the domestic industry.

\section{Market equilibrium}

Each firm maximizes profit with respect to technology, market presence on the domestic and foreign markets respectively, and output. The condition for presence on the individual market is non-negative operating profit, and for presence at all in at least one market, the total operating profit must at least be equal to the total fixed costs. The options on market presence leave several configurations depending on the parameters of demand and costs. As trade is in focus in this paper, we only look at the cases, where both firms are operating in the domestic market, and at least one of the firms is also present in the foreign market.

If both firms are present in both markets, duopoly prevails. Depending on the strategic choice of production technology, the following four outcomes may be considered: Both

\footnotetext{
${ }^{4}$ Melitz (2003) operates with fixed market access cost for both the domestic and foreign markets, with the latter of the largest size.
} 
firms establish a specialized technology (I); firm $I$ establishes a specialized technology, firm 2 establishes a non-specialized technology (II); firm 1 establishes a non-specialized technology, firm 2 establishes a specialized technology (III); both firms establish a nonspecialized technology (IV). Case (II) and (III) are symmetric and hence only the cases $(I),(I I)$ and $(I V)$ will be dealt with in the following.

The firms play a two-stage duopoly game. In the first stage, they simultaneously decide on technology specified by the alternative cost functions (2) or (3), and in the second stage they optimize output by playing Cournot. The model is solved by backward induction, i.e. quantities, prices and operating profits for the foreign and home markets are determined for a given technology in the first step. The next step is then to consider whether any of the firms have an incentive to change their technology or to leave one or both markets.

Using the standard Cournot analysis, Table 1 shows the solutions for profits for the case, where both producers are active in the home market as well as in the foreign market (see Appendix for the full solutions for output, prices and operating profits). 
Table 1. Profit matrix for alternative divisions of technologies across producers.

\begin{tabular}{|c|c|c|c|}
\hline & \multicolumn{2}{|c|}{ Firm 2} \\
\hline & & Specialized technology & Non-specialized technology \\
\hline \multirow{2}{*}{$\begin{array}{c}\text { Firm } \\
1\end{array}$} & $\begin{array}{l}\text { Specialized } \\
\text { technology }\end{array}$ & $\begin{array}{l}\left(\frac{a-c}{3}\right)^{2}+S\left(\frac{a-c-g}{3}\right)^{2}-f-m \\
\left(\frac{a-c}{3}\right)^{2}+S\left(\frac{a-c-g}{3}\right)^{2}-f-m\end{array}$ & $\begin{array}{l}\left(\frac{a-2 c+c^{*}}{3}\right)^{2}+S\left(\frac{a-2 c+c^{*}-g}{3}\right)^{2}-f-m ; \\
\left(\frac{a-2 c^{*}+c}{3}\right)^{2}+S\left(\frac{a-2 c^{*}+c-g}{3}\right)^{2}-f^{*}-m\end{array}$ \\
\hline & $\begin{array}{c}\text { Non- } \\
\text { specialized } \\
\text { technology }\end{array}$ & $\begin{array}{l}\left(\frac{a-2 c^{*}+c}{3}\right)^{2}+S\left(\frac{a-2 c^{*}+c-g}{3}\right)^{2}-f^{*}-m ; \\
\left(\frac{a-2 c+c^{*}}{3}\right)^{2}+S\left(\frac{a-2 c+c^{*}-g}{3}\right)^{2}-f-m ;\end{array}$ & $\begin{array}{l}\left(\frac{a-c^{*}}{3}\right)^{2}+S\left(\frac{a-c^{*}-g}{3}\right)^{2}-f^{*}-m \\
\left(\frac{a-c^{*}}{3}\right)^{2}+S\left(\frac{a-c^{*}-g}{3}\right)^{2}-f^{*}-m\end{array}$ \\
\hline
\end{tabular}

Note: It is assumed that both producers 1 and 2 produce and sell in both markets, $H$ and $F$.

The first term in each cell for producers 1 and 2 , respectively, is the operating profit in the domestic market. The second term is the operating profit in the foreign market and the last two terms are fixed production costs and fixed market access costs.

\section{Technology choice $e^{5}$}

Having solved the second stage, the Cournot optimization, we now turn to the first stage of choice of technology. The interesting result is that firm heterogeneity may turn out to be possible market equilibrium, i.e. one of the firms establishes a low variable and the

\footnotetext{
${ }^{5}$ In this and the following sub-section, we assume that parameters secure that there is duopolistic competition in both markets.
} 
other a low fixed cost technology. Case II (or case III) may thus be a sub-game perfect Nash-equilibrium for some values of the parameters.

As the cases $I I$ and $I I I$ are symmetric, we only look at case $I I$. Case $I I$, with mixed technologies, is a sub-game perfect Nash equilibrium if neither of the two producers has an incentive to reconsider their technology choice.

We first examine the strategic options for producer 1 given the initial choice of $I I$. Producer 1 will only abstain from shifting to a non-specialized technology (i.e. move from cell $I I$ to cell $I V$ ) if the profit by using a specialized technology is larger than the profit by switching to a non-specialized technology, i.e. if:

$$
\begin{aligned}
& \left(\frac{a-2 c+c^{*}}{3}\right)^{2}+S\left(\frac{a-2 c+c^{*}-g}{3}\right)^{2}-f-m> \\
& \left(\frac{a-c^{*}}{3}\right)^{2}+S\left(\frac{a-c^{*}-g}{3}\right)^{2}-f^{*}-m
\end{aligned}
$$

This gives the condition:

$$
\begin{aligned}
& g<g_{\max }=\left(\frac{1+S}{S}\right)(a-c)-\frac{9}{4 S} r \\
& \text { where: } r=\frac{(f+m)-\left(f^{*}+m\right)}{\left(c^{*}-c\right)}>0
\end{aligned}
$$

The interpretation is the following: The advantage of a low variable cost technology is contingent on large production runs, which only are fulfilled for variable trade costs below a threshold value $g_{\max }$. The threshold value, $g_{\max }$, depends positively on the size of the total market ( $a$ and/or $S$ ), because a larger market makes it more easy to realize large 
total production runs. ${ }^{6}$ The threshold value depends negatively on a ratio of cost parameters, $r$, which illustrates the cost advantage of using a low fixed cost technology compared to a low variable cost technology. A small value of $r$ caused by a large marginal cost difference $\left(c^{*}-c\right)$ and/or a small fixed cost difference $(f+m)-\left(f^{*}+m\right)$ indicates a favorable cost structure for a technology based on a low variable cost technology that is the specialized technology. ${ }^{7}$

We now turn to the strategic options of firm 2 given the initial choice of $I I$. Producer 2 will abstain from shifting to the specialized technology (i.e. move from cell $I I$ to cell $I$ ) if the profit by using the non-specialized technology is larger than the profit by switching to a specialized technology. Hence, producer 2 sticks to the non-specialized technology if:

$$
\begin{aligned}
& \left(\frac{a-2 c^{*}+c}{3}\right)^{2}+S\left(\frac{a-2 c^{*}+c-g}{3}\right)^{2}-f^{*}-m> \\
& \left(\frac{a-c}{3}\right)^{2}+S\left(\frac{a-c-g}{3}\right)^{2}-f-m
\end{aligned}
$$

This gives the condition:

$$
\begin{aligned}
& g>\mathrm{g}_{\min }=\left(\frac{1+S}{S}\right)\left(a-c^{*}\right)-\frac{9}{4 S}\left(\frac{(f+m)-\left(f^{*}+m\right)}{\left(c^{*}-c\right)}\right) \\
& =\left(\frac{1+S}{S}\right)\left(a-c^{*}\right)-\frac{9}{4 S} r
\end{aligned}
$$

The interpretation is similar to that of firm 1 above. To deter producer 2 from changing to a specialized technology, total production should be relatively limited, i.e. trade costs

\footnotetext{
${ }^{6}$ An increase in $S$ (for given $a$ ) is both an absolute and a relative increase in the foreign market, while an increase in $a$ is an absolute increase in the size of both markets, with unchanged relative sizes.

${ }^{7}$ Since we assume the same fixed market access costs for the two technologies, the fixed costs difference is $(f+m)-\left(f^{*}+m\right)=\left(f-f^{*}\right)$.
} 
should be above a threshold value. This threshold value, $g_{\min }$, depends positively on the total market size ( $a$ and/or $S$ ) and negatively on the relative cost advantage, $r$, operating on a specialized plant. Note, that since $c^{*}>c, g_{\max }>g_{\min }$. Hence, if $g_{\max }$ is positive, cases exist where a mixed technology will be chosen. If $g_{\min }$ is negative, the mixed technology will appear for $g<g_{\max }$, even in the case where $g=0$.

Figure 1 summarizes the conclusions so far. In case of high trade costs $\left(g>g_{\max }\right)$, both firms establish the non-specialized technology, i.e., the firms are symmetrical in technology. For medium trade costs $\left(g_{\min }<g<g_{\max }\right)$, one of the firms chooses the nonspecialized technology and the other the specialized. Beforehand, it is not possible, in this case of asymmetrical technologies, to tell how each of the two technologies will be assigned to each firm. As profit is largest for the firm with the specialized technology, this firm may have benefited from a first mover advantage. Finally, for low trade costs $\left(g<g_{\min }\right)$ both firms choose the specialized technology, i.e. establish a symmetrical technology.

Both $g_{\min }$ and $g_{\max }$ increase with market size ( $a$ and/or $S$ ), i.e. on a larger market the producers are more inclined to produce with the specialized technology. The fixed market access costs are basically irrelevant for the results, as the choice of technology only relates to the plant level, i.e. the market access costs are identical for the two alternative technologies. 
The basic reason, why technology heterogeneity arises in the model, is lumpiness of fixed capital reflected in indivisibility of fixed costs. The domestic and foreign markets are constrained in size. Moreover, the potential for sales in the foreign market is limited by trade costs. For medium trade costs $\left(g_{\min }<g<g_{\max }\right)$, the total quantity demanded in both markets will also loosely speaking be at a medium level. The strategic interaction at the market will match this by inducing one of the producers to be specialized and the other to be non-specialized. The specialized producer covers most of the total demand on the two markets utilizing his advantages of low marginal costs. The non-specialized producer covers the residual smaller part of the total demand utilizing his advantages of low fixed costs. The non-specialized producer has no incentive to change to the specialized technology, since the strategic interactions between the two firms will lead to a so large reduction in the goods price that his profit will fall. ${ }^{8}$

Figure 1. The structure of technologies and trade costs.

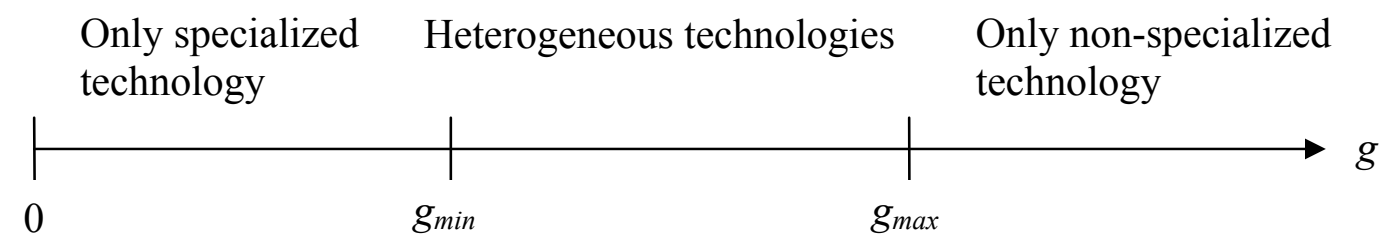

Note: Only values of $\mathrm{g} \geq 0$ are considered as trade subsidies are disregarded. Furthermore, the following analysis only looks at the case, where the values $g_{\min }$ and $g_{\max }$, calculated on the basis of duopolistic competition in both markets, are assumed to be positive.

\footnotetext{
${ }^{8}$ As argued by Mills and Smith (1996) the existence of equilibria with heterogeneous technologies does not hold for Bertrand interaction in stage two of the game. In such a case the non-specialized producer will be driven out of both markets as the specialized producer would set his price just slightly below $c^{*}$ in the home market and (in our framework) also slightly below $c^{*}+g$ in the foreign market.
} 
Firm size and exports

The heterogeneity of technology in case II (and III) translates both into differences in firm size and export status. The Appendix reports output for the two firms in case II $Q_{1}^{I I}$ and $Q_{2}^{I I}$ respectively, and the superior cost efficiency of the specialized producer obviously results in a larger production compared with the non-specialized producer. Formally, the difference in output of the two firms is proportionate to the differences in marginal costs of production; i.e.:

$$
Q_{1}^{I I}-Q_{2}^{I I}=(1+S)\left(c^{*}-c\right)>0
$$

The specialized producer is also the most export oriented. The Appendix reports the two producer's provision of output to the home market $q_{1}^{H, I I}$ and $q_{2}^{H, I I}$ respectively, and the provision of output to the foreign market $q_{1}^{F, I I}$ and $q_{2}^{F, I I}$ respectively. Using these results we get:

$$
\frac{q_{1}^{F, I I}}{q_{1}^{H, I I}}-\frac{q_{2}^{F, I I}}{q_{2}^{H, I I}}=\frac{\operatorname{Sg}\left(2 a+3\left(c^{*}-c\right)\right)}{\left(a-2 c^{*}+c\right)\left(a-2 c+c^{*}\right)}>0
$$

and hence, in relative (and also in absolute) terms, firm 1 is more oriented towards export than firm 2. This pattern of size and export orientation of firms is similar to the conclusions of models based on monopolistic competition in the 'new new' trade theory. 


\section{Market integration}

Variable trade costs, and in some cases also market access costs contribute, as shown in the previous analysis, to a segmentation of the two markets so different prices prevail. It is also shown that technology choice of the firms depends on trade costs. Market integration defined by a decrease in the barriers for trade influences the prices on the foreign market directly, but also indirect effects may materialize on both markets through an induced change of technology. This section deals with this issue.

\section{Technology change}

Let us first look at the effects of a decrease of the variable unit trade costs, $g$, and assume that both producers find it profitable to operate both in the home and the foreign markets. The effects of a decrease of $g$ follow straightforwardly from the previous section on Cournot Nash equilibrium, see Figure 1, which identifies the two threshold values $g_{\max }$ and $g_{\min }$ for separating the different technology configurations.

A decrease of $g$ which does not pass any of the two threshold values $g_{\max }$ and $g_{\min }$ leave technologies unchanged. The usual effects of market integration appear in these cases i.e. output of both firms increases due to an increase of exports. In the case of mixed technologies before and after market integration, market integration also changes the relative firm size (and market shares) and their export intensities. While the absolute difference in size of firms is independent of variable trade costs (see (6)), market integration increases the relative size (and market share) of the firm with the low fixed 
cost technology. The disadvantage of having high marginal costs of production decreases with better access to the foreign market, and hence the relative export orientation of the low fixed cost technology firm increases with increasing market integration (see (7)).

The more interesting cases appear, when the decrease of $g$ triggers a technology shift i.e., when $g$ initially is above but falls below one or both threshold values $g_{\max }$ and $g_{\min }$. If $g$ changes from $g>g_{\max }$ to $g_{\min }<g<g_{\max }$, both companies initially use the non-specialized technology, but after the decrease in trade costs one of the producers switches to the specialized technology (move from $I V$ to $I I / I I I$ in Table 1 ). For further market integration, where $g$ changes to $g<g_{\min }$, the other producer follows suit by adopting the specialized technology (move from II/ III to I in Table 1).

\section{Welfare}

The analysis of market integration and technology choice also provides some conclusions on welfare of the home country and the foreign country and for the two countries together, i.e. global welfare. Trade costs are throughout in the following welfare analysis perceived as real trade costs, i.e. no public budget effects appears. Hence, social welfare of the home country consists of consumer surplus in the home market and total producer surplus, which consists of operating profit in the two markets minus total fixed costs (fixed production costs plus market access costs). Social welfare of the foreign country consists of the consumer surplus exclusively, as no production takes place in this industry in the foreign country. The contributions to social welfare in the two countries are reported in the Appendix. 
A decrease of $g$ in the intervals, where technology is unchanged, leaves consumer and producer surplus in the home country unaffected because of market segmentation and the constant marginal costs independent of the output level. But the producers' profit increases with the decrease of $g$ in the foreign market and due to this, welfare in the home country, $W^{H}$, increases monotonically with the decrease of $g$. Welfare in the foreign country, $W^{F}$, only relates to consumer surplus in this country. The lower variable trade costs benefits the foreign consumers through a lower price and hence, welfare in the foreign country increases monotonically with the decrease of $g$. Global welfare, $W^{W}$, therefore also increases monotonically with the decrease of $g$; see Figure 2.

If a decrease of $g$ triggers a shift of technology the effects on welfare are more complex as prices on both markets decrease discontinuously. Consumer's surplus jumps discontinuously upwards in both countries in the wake of the drop in prices. However, the shift of technology affects the two producers' profit differently, and the two producers may therefore have opposing views on trade liberalization. A marginal decrease of $g$, which induces one of the producers to shift to a specialized technology, leaves this producer's profit approximately unchanged as the increase of his operating profit is offset by higher fixed production costs. The other producer, which does not change technology, suffers a loss, because he meets a more fierce competition in both markets due to the competitor's increased efficiency of variable input. A marginal decrease of $g$ therefore unambiguously reduces total profit of the two producers, and determining the sign of the welfare effects therefore requires a more careful analysis. 
The analysis of the effects on global welfare, when market integration triggers a technological restructuring, leaves the most interesting clear-cut results. Global welfare unambiguously increases, when a decline in trade costs induces a technological restructuring from a homogenous non-specialized technology to heterogeneous specialized and non-specialized technologies, while welfare unambiguously decreases, when a marginal decline of trade costs induces a restructuring from heterogeneous technologies to a homogeneous specialized technology. Calculating the effects on global welfare of a marginal decrease of $g$ for $g$ equal to $g_{\max }$ and $g_{\min }$, respectively gives (see the Appendix):

$\Delta W^{W}\left(g_{\max }\right)=\frac{(S+1)}{6}\left(c^{*}-c\right)^{2}>0$

$$
\Delta W^{W}\left(g_{\min }\right)=-\frac{(S+1)}{6}\left(c^{*}-c\right)^{2}<0
$$

The intuition behind these contrasting results of market integration and technology shift follows from the distinction between private costs savings for the individual producers and social costs savings. In both cases of a technology shift the producer, who restructures to a specialized technology, reaps a private variable costs saving on his output. However, the full amount of this gain is only a social gain in the case where both producers initially use the high variable costs technology. The social costs savings is here relatively large as the restructuring producer gets a lead in competitiveness and hence, captures the lion's part of the market. In the other case, where the producer with the non- 
specialized technology adopts the specialized technology similar to the other producer, the restructuring producer regains market shares by catching-up in efficiency with the producer, who already produces by low variable costs. A part of the private efficiency gain in variable costs is therefore not a social cost saving. The social savings in costs is only related to the cost savings on the initial relatively small output of the restructuring producer. The social benefits due to the increased cost efficiency and lower price is therefore insufficient to match the increase in fixed costs of the restructuring producer in the case where the non-specialized producer changes to a specialized technology similar to the other producer, and hence, the net effect in global welfare becomes negative in this case.

However, the asymmetric location of the firms in the two countries has distributional impacts on welfare between the countries, when technologies are restructured. A marginal decrease of trade costs at $g$ equal to $g_{\max }$ or $g_{\min }$ reduces the market price and the welfare in the foreign country jumps upwards due to larger consumers surplus, i.e. $\Delta W^{F}\left(g_{\max }\right)$ and $\Delta W^{F}\left(\mathrm{~g}_{\min }\right)$ are both positive. The welfare effect in the home country, when the technology changes from a symmetric, non-specialized technology to asymmetric technologies is given by:

$$
\Delta W^{H}\left(g_{\max }\right)=\frac{1}{18}\left(c^{*}-c\right)\left(4 S\left(a-c^{*}\right)+(3+6 S)\left(c^{*}-c\right)-9 S \frac{\left(f-f^{*}\right)}{\left(c^{*}-c\right)}\right)
$$

and the sign is uncertain. If the technological restructuring demands large extra fixed costs and the benefits of lower variable costs are limited, the welfare effect for the home country will be negative (as illustrated in Figure 2). 
If technology is restructured from asymmetric technologies to a symmetric specialized technology the welfare effect for the home country is unambiguously negative because of the negative global welfare effect $((9))$ and the positive welfare effect for the foreign country. Formally the welfare effect of the home country is given by (11):

$$
\Delta W^{H}\left(g_{\text {min }}\right)=\frac{1}{18}\left(c^{*}-c\right)\left(4 S\left(a-c^{*}\right)-(3+6 S)\left(c^{*}-c\right)-9 S \frac{\left(f-f^{*}\right)}{\left(c^{*}-c\right)}\right)
$$

which unambiguously is negative.

Figure 2: Welfare and variable trade costs: Both firms export

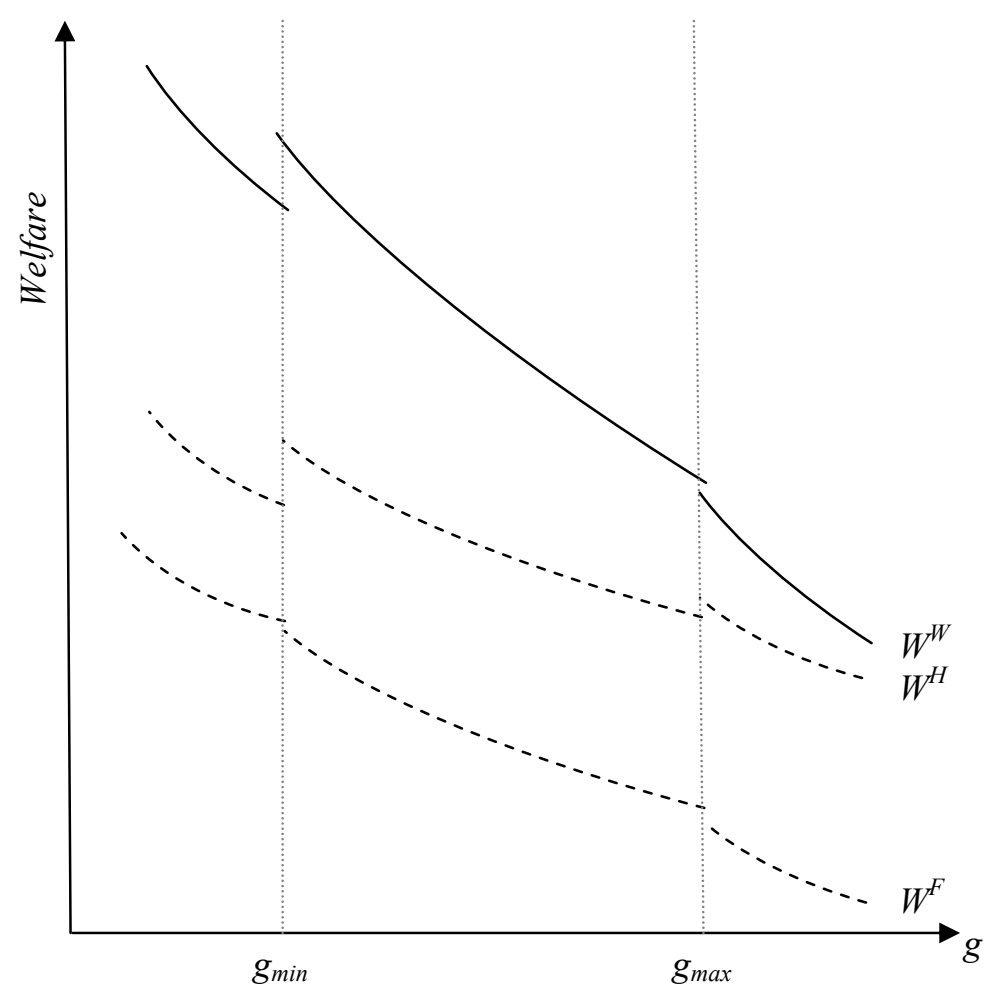

Note: $W^{H}, W^{F}$ and $W^{W}$ are welfare in country $H$, country $F$ and the world respectively. 
Figure 2 summarizes the results in the specific case where $\Delta W^{H} g_{\max }<0$. It appears from the sketched welfare profiles that a marginal decrease of $g$ which induces the producers to establish the same technology affects global welfare (and welfare in home country) negatively. However, as the Figure also illustrates, global welfare (and welfare in the home country) may increase if substantial reduction of trade costs takes place even though the producers establish the same technology 9 .

\section{A digression on a symmetrical market presence}

The analysis above has paid no attention to long-run conditions of entry and exit on the markets. If only two firms should be active in the longer term, each firm should have non-negative profit in contrast to the prospects for potential firms. We assume that this basic assumption is fulfilled. However, it does not follow from this that each firm will be active in the foreign market. Each firm is only active in the foreign market if the operating profit from the foreign market is sufficient to cover the fixed market access costs. If this condition precludes one of the firms from operating in the foreign market, the other firm is the sole provider of the foreign market, i.e. the other firm obtains a monopoly position in this market.

The size of variable trade costs varies negatively with operating profit in the foreign market. Hence, for each technology configuration, a critical value of variable trade costs, $\hat{g}$, exists, where the firm with the lowest operating profit in the foreign market can

\footnotetext{
${ }^{9}$ However, in the very special case, where $g_{\min }$ is small and initially $g$ is slightly above $g_{\min }$, trade costs can only be reduced to 0 and this may be insufficient to raise global welfare (or welfare in home country) to a level above its initial level for trade i.e. $W^{W}\left(g_{\min }\right)>W^{W}(0)\left(\right.$ or $\left.W^{H}\left(g_{\min }\right)>W^{H}(0)\right)$. In such cases free trade (in the given industry) is not necessarily optimal.
} 
exactly cover its fixed market access costs. If the variable trade costs exceed this critical value, one of the firms will drop out leaving the market to the other as monopolist. ${ }^{10}$

The results reported in Table 1 allow for calculation of the critical value of variable trade costs $(\hat{g})$ for the alternative technology configurations; specialized, specialized $(s, s)$; specialized, non-specialized $(s, n s)$, and non-specialized, non-specialized $(n s, n s)$, respectively:

$$
\begin{aligned}
& \hat{g}_{s, s}=(a-c)-3 \sqrt{\frac{m}{S}} \\
& \hat{g}_{s, n s}=\left(a-c^{*}\right)-\left(c^{*}-c\right)-3 \sqrt{\frac{m}{S}} \\
& \hat{g}_{n s, n s}=\left(a-c^{*}\right)-3 \sqrt{\frac{m}{S}}
\end{aligned}
$$

As $c^{*}<c$, we have $\hat{g}_{n s, n s}<\hat{g}_{s, n s}<\hat{g}_{s, s}$, i.e. the probability of exit of one of the firms from the foreign market is highest in case of the symmetric non-specialized technology configuration. For obvious reasons, all three critical values decrease for increasing market access costs, or put differently, the results in Table 1 for a duopoly on both markets only hold for moderate market access costs and limited variable trade costs.

For substantial market access costs, the actual value of trade costs $g$ may exceed one or more of the critical values of $\hat{g}\left(\hat{g}_{s, s}, \hat{g}_{s, n s}, \hat{g}_{n s, n s}\right)$. In this case, the variable trade costs

\footnotetext{
${ }^{10}$ If, contrary to the assumptions above, one of the producers is located in the home country and the other in the foreign country, the domestic producer will provide his home market and the smallest market may develop into a monopoly.
} 
influence the technology choice in a more complex way, because the market structure in the foreign market influences the technology choice.

If market access costs are substantial so one of the firms may be absent in the foreign market, market integration may influence both the technology choice and the market structure. Most relevant in a foreign trade context is the case, where $g>\hat{g}_{n s, n s}>g_{\max }$, i.e the trade costs only allow for one producer to operate in the foreign market. Although the variable cost structure would have indicated a non-specialized technology for both producers, the position of the producer with the monopoly in the foreign market may induce him to choose the specialized technology. This outcome is especially likely if $g$ and $\hat{g}_{n s, n s}$ are both close to $g_{\max }$. Market integration in the case where $g$ falls below $\hat{g}_{n s, n s}$ may therefore trigger a simultaneous technological restructuring and change of market structure. The reason is that the entry of the other firm will reduce the previous monopolist's sale at this market to a level where the non-specialized technology is optimal.

For the home country, the restructuring will give a welfare loss, both because of less consumer surplus as well as less producer surplus. The technology switch to a symmetric non-specialized technology raises the price level in home country making an inroad in consumer's surplus. Operating profit will also decrease in the home country due to higher variable costs. In the foreign market, the previous monopolist will suffer a loss in profit and the entrant will only be able just to cover the market access costs by operating profit in this market. The total profit for the two producers therefore decreases. For the foreign 
country, the welfare effect is uncertain, since the positive welfare effect of intensified competition is reduced by the costs increase, so the net change of welfare in the market is uncertain. For large cost increases $\left(c^{*}-c\right)$, the net welfare effect may therefore be negative.

\section{Conclusions}

Technology is a strategic parameter on markets with oligopoly. This may cause a diversification of technologies across firms' i.e. firm heterogeneity may appear as an endogenous outcome of the competitive game between firms in an industry. Additional reasons for firm heterogeneity may still exist. In a more general analysis firm heterogeneity may be a combined outcome of strategic considerations and, as assumed in the 'new-new' trade theory, exogenously firm specific cost parameters generated as a stochastic outcome of an initial investment.

In an open economy the variable trade costs are essential for the firm's market situation and hence, for the firm's choice of technology on markets with oligopoly. Market integration may therefore induce a shift in technology for one or more firms in the industry. Due to its second best nature, partial market integration may in some cases reduce global welfare and the welfare of the individual countries. This conclusion is in line with the conclusion on welfare in case of reciprocal dumping on segmented markets with oligopoly. 
It is shown in this paper that with respect to global welfare firm heterogeneity may in some cases be superior to a homogeneous technology generated as Cournot-Nash equilibrium. Market integration, which induces a switch from a heterogeneous to a homogenous technology based on the most efficient variable cost technology, may therefore impact global welfare negatively. So, in a process of ongoing market integration firms may be switching technologies to heterogeneity too late and subsequently to homogeneity too early, from a social point of view. However, patience will ensure a positive welfare effect.

\section{References}

Bernhard, A. B.; J. Eaton; B. Jensen and S. Kortum (2003), Plant and Productivity in International Trade, The American Economic Review, 93:1268-1290.

Bernhard, A. B. and J. B. Jensen (2004), Why some Firms Export, Review of Economics and Statistics, 86: 561-569.

Collie, D. R. (2006), Tariffs and Subsidies under Asymmetric Oligopoly: Ad Valorem Versus Specific Instruments. The Manchester School, 74(3):314-333.

Eckel, C. and J. P. Neary (2006), Multi-product Firms and Flexible Manufacturing in the Global Economy. Paper presented at $2^{\text {nd }}$ Otago Workshop in International trade, 2007.

Falvey, R. (1998), Mergers in Open Economies, The World Economy, 21(8): 1061-1076. 
Greenaway, D. and R. Kneller (2005), Firm Heterogeneity, Exporting and Foreign Direct Investment: Survey. GEP Research Paper Series, 32, 2005, University of Nottingham.

Helpman, E.; M. Melitz and S. Yeaple (2004), Export vs. FDI with Heterogeneous Firms, The American Economic Review, 94(1): 300-316.

Lahiri, S. and Y. Ono (1997), Asymmetric Oligopoly, International Trade, and Welfare: a Synthesis, Journal of Economics, 65(3):291-310.

Melitz, M. J. (2003), The Impact of Trade on Intra-Industry Reallocations and Aggregate Industry productivity. Econometrica, Vol. 71, No. 6.: 1695-1725.

Mills, D. E. and W. Smith (1996), It Pays to Be Different: Endogenous Heterogeneity of Firms in an Oligopoly. International Journal of Industrial Organization, 14: 317-329.

Montagna, C. (2001), Efficiency Gaps, Love of Variety and International Trade. Economica, 68: 27-44.

Schmitt, N. and Z. Yu (2001), Economies of Scale and the Volume of Intra-industry Trade. Economics Letters, 74:127-132.

Singh, N. and X. Vives (1984), Price and quantity competition in a differentiated duopoly, Rand Journal of Economics, 1584): 546-554. 


\section{Appendix}

\section{A: The solution of the Cournot model}

The Cournot-solution is reported below for the three cases $I, I I$, and $I V$ in Table 1 (III is symmetrical to $I I)$. The notation is: $q_{i}^{j}$ and $\pi_{i}^{j}$ are quantity and operating profit for producer $i(i=1,2)$ in market $j(j=H, F), Q_{i}$ total quantity for producer $i$, and $p^{j}$ and $C S^{j}$ consumer price and consumer surplus in market $j$ respectively.

I: Both producers produce at specialized plants.

$$
\begin{aligned}
& q_{1}^{H, I}=q_{2}^{H, I}=\frac{(a-c)}{3} ; q_{1}^{F, I}=q_{2}^{F, I}=\frac{S(a-c-g)}{3} \\
& Q_{1}^{I}=\left(q_{1}^{H, I}+q_{1}^{F, I}\right)=Q_{2}^{I}=\left(q_{2}^{H, I}+q_{2}^{F, I}\right)=\frac{(1+S)(a-c)-S g}{3} \\
& p^{H, I}=\frac{(a+2 c)}{3} \\
& p^{F, I}=\frac{(a+2 c+2 g)}{3} \\
& \pi_{1}^{H, I}=\pi_{2}^{H, I}=\left(\frac{a-c}{3}\right)^{2} ; \pi_{1}^{F, I}=\pi_{2}^{F, I}=S\left(\frac{a-c-g}{3}\right)^{2} \\
& \pi_{1}^{I}=\pi_{2}^{I}=\left(\frac{a-c}{3}\right)^{2}+S\left(\frac{a-c-g}{3}\right)^{2} \\
& C S^{H, I}=1 / 2\left(a-p_{i}^{H, I}\right)\left(q_{i}^{I, H, I}+q_{i}^{2, H, I}\right)=\frac{1}{2}\left(\frac{2 a-2 c}{3}\right)^{2} \\
& C S^{F, I}=1 / 2\left(a-p^{F, I}\right)\left(q_{1}^{F, I}+q_{2}^{F, I}\right)=\frac{\mathrm{S}}{2}\left(\frac{2 a-2 c-2 g}{3}\right)^{2}
\end{aligned}
$$


II: Producer 1 produces at a specialized plant; producer 2 produces at a non-specialized plant.

$$
\begin{aligned}
& q_{1}^{H, I I}=\frac{\left(a-2 c+c^{*}\right)}{3} ; q_{1}^{F, I I}=\frac{S\left(a-2 c+c^{*}-g\right)}{3} ; Q_{1}^{I I}=\left(q_{1}^{H, I I}+q_{1}^{F, I I}\right)=\frac{(1+S)\left(a-2 c+c^{*}\right)-S g}{3} \\
& q_{2}^{H, I I}=\frac{\left(a-2 c^{*}+c\right)}{3} ; q_{2}^{F, I I}=\frac{S\left(a-2 c^{*}+c-g\right)}{3} ; Q_{2}^{I I}=\left(q_{2}^{H, I I}+q_{2}^{F, I I}\right)=\frac{(1+S)\left(a-2 c^{*}+c\right)-S g}{3} \\
& p^{H, I I}=\frac{\left(a+c+c^{*}\right)}{3} \\
& p^{F, I I}=\frac{\left(a+c+c^{*}+2 g\right)}{3} \\
& \pi_{1}^{H, I I}=\left(\frac{a-2 c+c^{*}}{3}\right)^{2} ; \pi_{1}^{F, I I}=S\left(\frac{a-2 c+c^{*}-g}{3}\right)^{2} \\
& \pi_{1}^{I I}=\left(\frac{a-2 c+c^{*}}{3}\right)^{2}+S\left(\frac{a-2 c+c^{*}-g}{3}\right)^{2} \\
& \pi_{2}^{H, I I}=\left(\frac{a-2 c^{*}+c}{3}\right)^{2} ; \pi_{2}^{F, I I}=S\left(\frac{a-2 c^{*}+c-g}{3}\right)^{2} \\
& \pi_{2}^{I I}=\left(\frac{a-2 c^{*}+c}{3}\right)^{2}+S\left(\frac{a-2 c^{*}+c-g}{3}\right)^{2} \\
& C S^{H, I I}=1 / 2\left(a-p^{H, I I}\right)\left(q_{1}^{H, I I}+q_{2}^{H, I I}\right)=\frac{1}{2}\left(\frac{2 a-c^{*}-c}{3}\right)^{2} \\
& C S^{F, I I}=1 / 2\left(a-p^{F, I I}\right)\left(q_{1}^{F, I I}+q_{2}^{F, I I}\right)=\frac{\mathrm{S}}{2}\left(\frac{2 a-c^{*}-c-2 g}{3}\right)^{2}
\end{aligned}
$$


IV: Both producers produce at a non-specialized plant.

$$
\begin{aligned}
& q_{1}^{H, I V}=q_{2}^{H, I V}=\frac{\left(a-c^{*}\right)}{3} ; q_{1}^{F, I V}=q_{2}^{F, I V}=\frac{S\left(a-c^{*}-g\right)}{3} ; \\
& Q_{1}^{I V}=\left(q_{1}^{H, I V}+q_{1}^{F, I V}\right)=Q_{2}^{I V}=\left(q_{2}^{H, I V}+q_{2}^{F, I V}\right)=\frac{(1+S)\left(a-c^{*}\right)-S g}{3} \\
& p^{H, I V}=\frac{\left(a+2 c^{*}\right)}{3} \\
& p^{F, I V}=\frac{\left(a+2 c^{*}+2 g\right)}{3} ; \\
& \pi_{1}^{H, I V}=\pi_{2}^{H, I V}=\left(\frac{a-c^{*}}{3}\right)^{2} ; \pi_{1}^{F, I V}=\pi_{2}^{F, I V}=S\left(\frac{a-c^{*}-g}{3}\right)^{2} \\
& \pi_{1}^{I V}=\pi_{2}^{I V}=\left(\frac{a-c^{*}}{3}\right)^{2}+S\left(\frac{a-c^{*}-g}{3}\right)^{2} \\
& C S^{H, I V}=1 / 2\left(a-p_{i}^{H, I V}\right)\left(q_{1}^{H, I V}+q_{2}^{H, I V}\right)=\frac{1}{2}\left(\frac{2 a-2 c^{*}}{3}\right)^{2} \\
& C S^{F, I V}=1 / 2\left(a-p^{F, I V}\right)\left(q_{1}^{F, I V}+q_{2}^{F, I V}\right)=\frac{\mathrm{S}}{2}\left(\frac{2 a-2 c^{*}-2 g}{3}\right)^{2}
\end{aligned}
$$

\section{B. The sufficient conditions for two firms operating on both markets}

\section{a) Non-exit condition}

In the short run, the firms should have non-negative operating profits on both markets. This is the case if $\min \left\{(a-c),\left(a-c^{*}\right),\left(a-2 c+c^{*}-g\right),\left(a-2 c^{*}+c-g\right)\right\} \geq 0$. The binding condition thus becomes: $\left(a-2 c^{*}+c-g\right) \geq 0$, i.e. in competition with the specialized firm the nonspecialized firm should be able to export without negative operating profit.

In the long run, the firms should have non-negative total profit. Inspection of Table 1 gives the following rankings of operating profits for the two producers: 
$\pi_{1}^{I I}>\pi_{1}^{I}=\pi_{2}^{I}>\pi_{1}^{I V}=\pi_{2}^{I V}>\pi_{2}^{I I}$

The lowest operating profit for a firm using a specialized technology is thus $\pi_{l}^{I}$ and for a non-specialized firm $\pi_{2}^{I I}$. Hence, profit is non-negative irrespective the technology configuration, if the following two conditions are fulfilled:

$\pi_{1}^{I} \geq(f+m)$ and $\pi_{2}^{I I} \geq\left(f^{*}+m\right)$. Using the expression for operating profits, these conditions may be written as:

$\frac{(a-c)^{2}+S(a-c-g)^{2}}{9} \geq(f+m)$

and

$\frac{\left(a-2 c^{*}+c\right)^{2}+S\left(a-2 c^{*}+c-g\right)^{2}}{9} \geq(f *+m)$

The conditions are satisfied if the fixed plant costs plus market access costs are moderate relative to obtainable operating profit.

\section{b) Non-entry condition}

Potential new firms should not have an incentive to enter. If a new firm enters, the operating profit of the new firm will be lower than the operating profit for any of the incumbent firms in duopoly, because of the intensified competition. To deter potential firms from entering, potential operating profit of the new firm should thus be lower than the total fixed costs irrespective of choice of plant. This is the case if fixed plant and market access costs are substantial relative to operating profit for the two firms in duopoly. 


\section{Welfare effects of technology shifts}

This section reports the welfare effects of a marginal reduction of $g$ for $g$ equal to $g_{\max }$ and $g_{\min }$, respectively, i.e. the change of $g$ triggers a technology shift from $I V$ to $I I$ or from $I I$ to $I$. The changes in welfare are calculated for the home country, $\Delta W^{H}$, the foreign country, $\Delta W^{F}$, and globally $\Delta W^{W}$. The calculation of the welfare effects uses the results in section A.

a. $g=g_{\max }$ : Change of the technology configuration from IV to II

a.1. $\Delta W^{H}\left(g_{\max }\right)$

The change in welfare in the home country $\Delta W^{H}\left(g_{\max }\right)$ is given by the change in consumer surplus in the home country plus the change in total profit of both firms. The change in consumer surplus is given by:

$\Delta C S^{H}\left(g_{\max }\right)=\frac{1}{18}\left(c^{*}-c\right)\left[4\left(a-c^{*}\right)+\left(c^{*}-c\right)\right]$

A marginal decrease of $g$ for $g=g_{\max }$ leaves total profit unchanged for the producer, who switches from the non-specialized to the specialized technology, as the increase in total operating profit for this producer is off-set by an increase of fixed costs.

The change in profit for the non-specialized producer 2 is equal the difference in the operating profit for this producer $\Delta \pi_{2}\left(g_{\max }\right)$, i.e.:

$\Delta \pi_{2}\left(g_{\max }\right)=-\frac{1}{9}\left(c^{*}-c\right)\left[\left(2\left(a-c^{*}\right)-\left(c^{*}-c\right)\right)+S\left(2\left(a-c^{*}-g_{\max }\right)-\left(c^{*}-c\right)\right)\right]$ 
The total home market welfare effect is

$\Delta W^{H}\left(g_{\max }\right)=\frac{1}{18}\left(c^{*}-c\right)\left[(3+2 S)\left(c^{*}-c\right)-4 S\left(a-c^{*}-g_{\max }\right)\right]$

Inserting

$g_{\max }=2(a-c)-\frac{9}{4} \frac{\left(f-f^{*}\right)}{\left(c^{*}-c\right)}$

gives

$\Delta W^{H}\left(g_{\max }\right)=\frac{1}{18}\left(c^{*}-c\right)\left(4 S\left(a-c^{*}\right)+(3+6 S)\left(c^{*}-c\right)-9 S \frac{\left(f-f^{*}\right)}{\left(c^{*}-c\right)}\right)$

a.2. $\Delta W^{F}\left(g_{\max }\right)$

The change in welfare in the foreign country, $\Delta W^{F}\left(g_{\max }\right)$, is given by the change in consumer surplus exclusively, i.e.:

$$
\Delta W^{F}\left(g_{\max }\right)=\Delta C S^{F}\left(g_{\max }\right)=\frac{S}{18}\left(c^{*}-c\right)\left[4\left(a-c^{*}-g_{\max }\right)+\left(c^{*}-c\right)\right]>0
$$

a.3. $\Delta W^{W}\left(g_{\max }\right)$

The change in world welfare, $\Delta W^{W}\left(g_{\max }\right)$, equals the change in welfare in the home plus the foreign country:

$W^{W}\left(g_{\max }\right)=W^{H}\left(g_{\max }\right)+W^{F}\left(g_{\max }\right)=\frac{(S+1)}{6}\left(c^{*}-c\right)^{2}>0$

b. $g=g_{\min }$ : Change of the technology configuration from II to I

b.1. $\Delta W^{H}\left(g_{\text {min }}\right)$

The change in consumer surplus is given by: 
$\Delta C S^{H}\left(g_{\min }\right)=\frac{1}{18}\left(c^{*}-c\right)\left[4(a-c)-\left(c^{*}-c\right)\right]$

The change of total profit equals the change in operating profit for the specialized producer as the change in profit for the switching non-specialized producer is 0 . The change in total profit is thus given by:

$\Delta \pi_{1}\left(g_{\min }\right)=-\frac{1}{9}\left(c^{*}-c\right)\left[\left(2(a-c)+\left(c^{*}-c\right)\right)+S\left(2\left(a-c-g_{\min }\right)+\left(c^{*}-c\right)\right)\right]$

Hence, the total home market welfare effect is

$$
\Delta W^{H}\left(g_{\min }\right)=\frac{1}{18}\left(c^{*}-c\right)\left[-(3+2 S)\left(c^{*}-c\right)-4 S\left(a-c-g_{\min }\right)\right]
$$

Inserting

$$
g=g_{\min }=2\left(a-c^{*}\right)-\frac{9}{4} \frac{\left(f-f^{*}\right)}{\left(c^{*}-c\right)}
$$

gives

$$
\Delta W^{H}\left(g_{\min }\right)=\frac{1}{18}\left(c^{*}-c\right)\left(4 S\left(a-c^{*}\right)-(3+6 S)\left(c^{*}-c\right)-9 S \frac{\left(f-f^{*}\right)}{\left(c^{*}-c\right)}\right)
$$

\section{b.2. $\Delta W^{F}\left(g_{\min }\right)$}

The change in total welfare in the foreign country, $\Delta W^{F}\left(g_{\text {min }}\right)$, is given by the change in consumer surplus exclusively:

$$
\Delta W^{F}\left(g_{\min }\right)=\Delta C S^{F}\left(g_{\min }\right)=\frac{S}{18}\left(c^{*}-c\right)\left[4\left(a-c-g_{\min }\right)-\left(c^{*}-c\right)\right]>0
$$

\section{b.3. $\Delta W^{W}\left(g_{\min }\right)$}

The change in world welfare $\Delta W^{W}\left(g_{\text {min }}\right)$ is thus: 


$$
W^{W}\left(g_{\min }\right)=W^{H}\left(g_{\text {min }}\right)+W^{F}\left(g_{\text {min }}\right)=-\frac{(S+1)}{6}\left(c^{*}-c\right)^{2}<0
$$

Since $\Delta W^{W}\left(g_{\text {min }}\right)<0$ and $\Delta W^{F}\left(g_{\text {min }}\right)>0$, we have $\Delta W^{H}\left(g_{\text {min }}\right)<0$. 